\title{
Sonic and Photonic Crystals
}

\author{
Lien-Wen Chen ${ }^{1, *}$ and Jia-Yi Yeh ${ }^{2}$ \\ 1 Department of Mechanical Engineering, National Cheng Kung University, Tainan City 701, Taiwan \\ 2 Department of Information Management, Chung Hwa University of Medical Technology, \\ Tainan City 717, Taiwan; yeh@mail.hwai.edu.tw \\ * Correspondence: chenlw@mail.ncku.edu.tw
}

Received: 29 October 2020; Accepted: 31 October 2020; Published: 3 November 2020

check for updates

Sonic/phononic crystals named acoustic/sonic band gap media are the elastic analogues of photonic crystals and have received renewed attention recently in many acoustic applications. Photonic crystals have a periodic dielectric modulation with a spatial scale on the order of the optical wavelength. Design and optimization of the photonic crystals can be utilized in many applications by combining factors related to the combinations of intermixing materials, lattice symmetry, lattice constant, filling factor, shape of the scattering object, and thickness of a structural layer.

The Special Issue on "Sonic and Photonic Crystals" is focused on broad applications of the results involving characterizations of the sonic and photonic crystal properties.

The applications of photonic crystals were presented in this special issue. The gradient cavity, waveguide, switch, and spatial beam filtering with autocloned photonic crystals were studied and discussed [1-6]. The metamaterial of crystal structure can be found in [7-10], and the negative effects of those star-shaped structures were investigated and the applications in those studies were also discussed.

The elastic wave propagations in the phononic crystals are also interesting topics. The elastic wave propagations in the metamaterials, the elastic piezoelectric phononic crystals, and the energy harvesting phononic devices are listed in [11-13].

More about the photonic crystal applications also can be found in following studies. The deterministic insertion of KTP $\left(\mathrm{KTiOPO}_{4}\right)$ nanoparticles into polymeric structures, flexible photonic nanojet by cylindrical graded-index lens, and photonic crystal fiber investigations were presented [14-17]. Design of the polarization splitter and converter based on square lattice photonic crystal fiber were investigated in [18,19], and the polarization characteristics of photonic crystals were discussed in those investigation. Finally, the review paper of recent advances in colloidal photonic crystal-based anti-counterfeiting materials was introduced in [20].

This Special Issue presents and discusses the work of scientists studying a wide range of sonic/photonic crystal applications toward advancing this field.

Through the publications and discussions of the research on sonic/phononic crystals, the researchers can obtain effective and valuable results and improve their future development in related fields. Those devices can be utilized in mechanical and physical applications and also be used in design for novel applications based on investigations in this special issue.

Funding: This research received no external funding.

Conflicts of Interest: The authors declare no conflict of interest.

\section{References}

1. Ren, L.; Li, Y.; Li, N.; Chen, C. Trapping and Optomechanical Sensing of Particles with a Nanobeam Photonic Crystal Cavity. Crystals 2019, 9, 57. [CrossRef]

2. Azizpour, M.R.J.; Soroosh, M.; Dalvand, N.; Seifi-Kavian, Y. All-Optical Ultra-Fast Graphene-Photonic Crystal Switch. Crystals 2019, 9, 461. [CrossRef] 
3. Francis, H.; Chen, S.; Che, K.-J.; Hopkinson, M.; Jin, C.-Y. Photonic Crystal Cavity-Based Intensity Modulation for Integrated Optical Frequency Comb Generation. Crystals 2019, 9, 493. [CrossRef]

4. Jao, R.-F.; Lin, M.-C. Quantitative Analysis of Photon Density of States for One-Dimensional Photonic Crystals in a Rectangular Waveguide. Crystals 2019, 9, 576. [CrossRef]

5. Wang, P.-Y.; Lai, Y.-C.; Cheng, Y.-C. Spatial Beam Filtering with Autocloned Photonic Crystals. Crystals 2019, 9, 585. [CrossRef]

6. Huang, N.-N.; Chung, Y.-C.; Chiu, H.-T.; Hsu, J.-C.; Lin, Y.-F.; Kuo, C.-T.; Chang, Y.-W.; Chen, C.-Y.; Lin, T.-R. Dual Photonic-Phononic Crystal Slot Nanobeam with Gradient Cavity for Liquid Sensing. Crystals 2020, 10, 421. [CrossRef]

7. Luan, P.-G. Bubbly Water as a Natural Metamaterial of Negative Bulk-Modulus. Crystals 2019, 9, 457. [CrossRef]

8. Nguyen, T.-P.; Tien, T.Q.; Tong, Q.C.; Lai, N.D. An Optimization of Two-Dimensional Photonic Crystals at Low Refractive Index Material. Crystals 2019, 9, 442. [CrossRef]

9. Li, Q.; Guo, Y.; Wang, Y.; Zhang, H. Band Tunability of Coupled Elastic Waves along Thickness in Laminated Anisotropic Piezoelectric Phononic Crystals. Crystals 2019, 9, 426. [CrossRef]

10. Chang, S.-Y.; Chen, C.-D.; Yeh, J.-Y.; Chen, L.-W. Elastic Wave Propagation of Two-Dimensional Metamaterials Composed of Auxetic Star-Shaped Honeycomb Structures. Crystals 2019, 9, 121. [CrossRef]

11. Lv, X.-F.; Fang, X.; Zhang, Z.-Q.; Huang, Z.; Chuang, K.-C. Highly Localized and Efficient Energy Harvesting in a Phononic Crystal Beam: Defect Placement and Experimental Validation. Crystals 2019, 9, 391. [CrossRef]

12. Liang, X.; Wang, T.; Jiang, X.; Liu, Z.; Ruan, Y.; Deng, Y. A Numerical Method for Flexural Vibration Band Gaps in a Phononic Crystal Beam with Locally Resonant Oscillators. Crystals 2019, 9, 293. [CrossRef]

13. Deng, T.; Zhang, S.; Gao, Y. A Magnetic-Dependent Vibration Energy Harvester Based on the Tunable Point Defect in 2D Magneto-Elastic Phononic Crystals. Crystals 2019, 9, 261. [CrossRef]

14. Nguyen, D.T.T.; Lai, N.D. Deterministic Insertion of KTP Nanoparticles into Polymeric Structures for Efficient Second-Harmonic Generation. Crystals 2019, 9, 365. [CrossRef]

15. Liu, C.-Y. Flexible Photonic Nanojet Formed by Cylindrical Graded-Index Lens. Crystals 2019, 9, 198. [CrossRef]

16. Zhang, H.; Han, D.; Xi, L.; Zhang, Z.; Zhang, X.; Li, H.; Zhang, X. Two-Layer Erbium-Doped Air-Core Circular Photonic Crystal Fiber Amplifier for Orbital Angular Momentum Mode Division Multiplexing System. Crystals 2019, 9, 156. [CrossRef]

17. Yang, J.; Zhang, H.; Zhang, X.; Li, H.; Xi, L. Analysis of the Transmission Characteristic and Stress-Induced Birefringence of Hollow-Core Circular Photonic Crystal Fiber. Crystals 2019, 9, 128. [CrossRef]

18. Xu, Q.; Luo, W.; Li, K.; Copner, N.; Lin, S.-B. Design of Polarization Splitter via Liquid and Ti Infiltrated Photonic Crystal Fiber. Crystals 2019, 9, 103. [CrossRef]

19. Zhang, Z.; Tsuji, Y.; Eguchi, M.; Chen, C.-P. Polarization Converter Based on Square Lattice Photonic Crystal Fiber with Double-Hole Units. Crystals 2019, 9, 58. [CrossRef]

20. Pan, M.; Wang, L.; Dou, S.; Zhao, J.; Xu, H.; Zhang, L.; Li, X. Recent Advances in Colloidal Photonic Crystal-Based Anti-Counterfeiting Materials. Crystals 2019, 9, 417. [CrossRef]

Publisher's Note: MDPI stays neutral with regard to jurisdictional claims in published maps and institutional affiliations.

(C) 2020 by the authors. Licensee MDPI, Basel, Switzerland. This article is an open access article distributed under the terms and conditions of the Creative Commons Attribution (CC BY) license (http://creativecommons.org/licenses/by/4.0/). 